\title{
T Lymphocyte Ontogeny in Adenosine Deaminase-deficient Severe Combined Immune Deficiency after Treatment with Polyethylene Glycol-modified Adenosine Deaminase
}

\author{
Kenneth Weinberg, * Michael S. Hershfield, ${ }^{*}$ John Bastian, ” Donald Kohn, * \\ Leonard Sender, * Robertson Parkman, * and Carl Lenarsky* \\ *Division of Research Immunology/Bone Marrow Transplantation, Childrens Hospital Los Angeles, Department of Pediatrics, \\ University of Southern California School of Medicine, Los Angeles, California 90027; ${ }^{\ddagger}$ Department of Medicine, Duke University \\ School of Medicine, Durham, North Carolina 27710; and ${ }^{\S}$ Children's Hospital San Diego, San Diego, California 92123
}

\begin{abstract}
Adenosine deaminase (ADA) deficiency causes severe combined immune deficiency (SCID) by interfering with the metabolism of deoxyadenosine, which is toxic to $T$ lymphocytes at all stages of differentiation. Enzyme replacement with polyethylene glycol-modified ADA (PEG-ADA) has been previously shown to correct deoxyadenosine metabolism and improve mitogen-induced $T$ lymphocyte proliferation. We studied the biochemical and immunologic effects of PEG-ADA in two infants with ADA-deficient SCID. While in a catabolic state, higher doses of PEG-ADA than previously described were required to normalize deoxyadenosine metabolism. After biochemical improvement, the patients recovered immune function in a pattern similar to that observed in normal thymic ontogeny and in patients with immunological reconstitution after bone marrow transplantation. Immune reconstitution was marked by the sequential appearance in the peripheral blood of phenotypic $T$ lymphocytes corresponding to successive stages of thymic differentiation. Functional reconstitution was marked by the successive appearance of mitogen responses dependent on exogenous in vitro IL-2, mitogen responses not requiring exogenous IL-2, antigen-specific responses dependent on exogenous IL-2, and finally, antigen-specific responses not requiring exogenous IL-2. Natural killer function was tested in one patient and normalized with PEG-ADA therapy. Optimal PEG-ADA therapy appears to normalize thymic differentiation in ADA-deficient SCID, resulting in normal antigen-specific immune function. (J. Clin. Invest. 1993. 92:596-602.) Key words: thymic ontogeny $\bullet$ IL-2 - enzyme replacement • bone marrow transplant • immune reconstitution
\end{abstract}

\section{Introduction}

In severe combined immunodeficiency disease (SCID), ${ }^{1} \mathrm{~T}$ and $B$ lymphocyte dysfunction predisposes to life-threatening

Address correspondence to Dr. Kenneth Weinberg, Division of Research Immunology / Bone Marrow Transplantation, Childrens Hospital Los Angeles, 4650 Sunset Blvd. \#62, Los Angeles, CA 90027.

Received for publication 10 September 1991 and in revised form 19 January 1993.

1. Abbreviations used in this paper: ADA, adenosine deaminase; dAdo, deoxyadenosine; dAXP, deoxyribonucleotide; EC, effector cells; IVIg, intravenous immunoglobulin; NK, natural killer; PEG-ADA, polyeth-

J. Clin. Invest.

(c) The American Society for Clinical Investigation, Inc.

0021-9738/93/08/0596/07 \$2.00

Volume 92, August 1993, 596-602 infections (1). The etiology of SCID in most cases is unknown, but $20 \%$ of patients are deficient in adenosine deaminase (ADA), an enzyme expressed at very high levels in immature thymocytes (2). Toxicity of the ADA substrate, deoxyadenosine (dAdo), is thought to be responsible for the profound $T$ lymphopenia of ADA-deficient infants and fetuses (3). T lymphocytes at all stages of maturation are sensitive to dAdo, so that the exact stage at which $\mathrm{T}$ lymphocyte development is interrupted and the ultimate nature of the responsible lesion are unclear.

Since 1986, enzyme replacement therapy for ADA deficiency has been possible with intramuscular injections of purified bovine ADA, modified with polyethylene glycol (PEG) to prolong its circulating life and reduce immunogenicity $(4,5)$. PEG-modified ADA (PEG-ADA) has been used in patients who lack an HLA-identical sibling bone marrow donor or in whom transplantation of T cell-depleted, HLA-haploidentical (parental) marrow had been ineffective or was considered an unacceptable alternative. A fundamental difference in the outcome of therapy with PEG-ADA and haploidentical transplantation is that PEG-ADA patients develop autologous $T$ lymphocyte function, while the $T$ lymphocytes of transplanted patients are exclusively of donor origin.

Since untreated ADA-deficient SCID patients have small numbers of $\mathrm{T}$ lymphocytes, it has not been possible to determine whether $T$ lymphocytes that appear after PEG-ADA therapy result from the clonal expansion of pre-existing $T$ lymphocytes that escaped intrathymic selection and metabolic death due to ADA deficiency or whether PEG-ADA permits the differentiation of $T$ lymphocytes de novo from immature thymic precursors. To determine the origin of $\mathrm{T}$ lymphocytes after PEG-ADA therapy, we examined the pattern of immunological reconstitution and antigen-specific function of $\mathrm{T}$ lymphocytes of two PEG-ADA-treated patients.

\section{Methods}

\section{Biochemical studies}

Heparinized venous blood was separated into plasma and packed red cell fractions, which were frozen until analysis. Plasma levels of ADA activity, levels of total erythrocyte adenine ribo- and deoxyribonucleotides (dAXP) and erythrocyte levels of $S$-adenosylhomocysteine hydrolase (SAHase) activity were determined as previously described (6-9).

ylene glycol-modified adenosine deaminase; PHA, phytohemagglutinin; RBC, red blood cells; SAHase, $S$-adenosylhomocysteine hydrolase; SCID, severe combined immunodeficiency disease; TC, target cells; TCR, T cell receptor. 


\section{Immunophenotyping}

Peripheral blood mononuclear cells were isolated by Ficoll-Hypaque (Pharmacia LKB Biotechnology Inc., Piscataway, NJ) density centrifugation. $1 \times 10^{6}$ cells were stained with optimal concentrations of each monoclonal antibody, washed twice in a Sorvall Cell Washer (Ortho Diagnostic Systems Inc., Raritan, NJ) with Immusal (Baxter Diagnostics Inc., McGaw Park, IL) and fixed in 1\% paraformaldehyde. The cells were analyzed on a FACScan $\circledast$ (Becton Dickinson and Co. Mountain View, CA) flow cytometer. Routinely, staining with fluorescein isothiocyanate or phycoerythrin-labeled monoclonal antibodies directed at CD7, CD2, CD3, CD4, CD8, and CD1 (Becton-Dickinson and Co., and Coulter Corp., Hialeah, FL) was performed. Background staining was determined by incubation with isotype-specific control ascites. The percentage of positive cells with specific monoclonal antibodies was determined by subtraction of background staining from the specific staining, using a scale of log fluorescence intensity. Dim staining for $\mathrm{CD} 3$ was defined by a fluorescence intensity between the maximum background staining ( $99 \%$ negative) with control ascites and fivefold greater than the background. Bright CD3 staining was defined as greater than fivefold brighter than the maximum background.

\section{Proliferation assays}

$1 \times 10^{5}$ mononuclear cells were incubated in round-bottom wells in 96-well microtiter plates in RPMI 1640 medium with $2 \mathrm{mM}$ L-glutamine, $50 \mathrm{U} / \mathrm{ml}$ penicillin, $5 \mu \mathrm{g} / \mathrm{ml}$ streptomycin, and $5 \%$ human $A$ serum. For mitogen assays, the cells were incubated with either medium alone or with phytohemagglutinin (PHA; Difco Laboratories Inc., Detroit, MI) at concentrations of 1:250, 1:1,250, or 1:6,250. At 72 $\mathrm{h}$ the cells were pulsed overnight with $1 \mu \mathrm{Ci}\left[{ }^{3} \mathrm{H}\right]$ thymidine and harvested after $16 \mathrm{~h}$. For antigen-specific proliferation, the cells were incubated with either medium alone, tetanus toxoid 1:320 (Connaught Labs Ltd., Willowdale, Ontario, Canada), or candida extract 1:160 (Hollister-Stier Miles Inc., Elkhart, IN). Antigen-specific proliferation was measured as for PHA but at $120 \mathrm{~h}$ instead of $72 \mathrm{~h}$. For some experiments, recombinant IL-2 (Cetus Corp., Emeryville, CA) was added at a final concentration of $60 \mathrm{IU} / \mathrm{ml}$. All values are the mean of triplicate wells. Results of proliferation assays were expressed as $\Delta \mathrm{cpm}$ (cpm, test - cpm, background) or as stimulation index (S.I.) (cpm, test/cpm, background).

\section{Natural killer cytotoxicity assays}

Lysis of the K562 leukemia cell line was used to measure natural killer (NK) activity. K562 target cells (TC) were radiolabeled by incubation for $1 \mathrm{~h}$ at $37^{\circ} \mathrm{C}$. Freshly isolated peripheral blood mononuclear cells were used as the source of effector cells (EC). $1 \times 10^{4}$ TC were incubated with EC in V-bottom wells at $37^{\circ} \mathrm{C}$ for $4 \mathrm{~h}$ at EC:TC ratios of 12:1, 25:1, and 50:1. EC-induced lysis of TC was determined by measuring radioactivity in supernatants after incubation. Total release was determined by detergent (NP-40) lysis of TC and spontaneous release by measuring radioactivity after incubation of $\mathrm{TC}$ with media alone. Results were expressed as the mean of triplicate wells. The percent specific lysis of patient and control samples was expressed as:

$\frac{\text { test release }(\mathrm{cpm})-\text { spontaneous release }(\mathrm{cpm})}{\text { total release }(\mathrm{cpm})-\text { spontaneous release }(\mathrm{cpm})} \times 100$.

\section{Patient summaries}

Patient 1. Patient 1 is the full-term product of a normal pregnancy and delivery in a 29-yr-old G3P2 woman. The infant was well until 6 wk of age, when he presented to Childrens Hospital Los Angeles with bilateral interstitial pneumonia. He was treated empirically with antibiotics for $2 \mathrm{wk}$. No organism was isolated. At 3.5 mo of age, the patient was admitted again to Childrens Hospital Los Angeles with recurrent bilateral interstitial pneumonia. Viral culture demonstrated parainfluenza type 2 . He was admitted again at age 5.5 mo with recurrent parainfluenza type 2 pneumonia, which was treated with aerosolized ribavirin. By this time failure to thrive was evident. Immunological evaluation revealed very low numbers of $\mathrm{T}$ lymphocytes (absolute $\mathrm{CD} 3$ cell number $\left.=300 / \mathrm{mm}^{3}\right)$ and complete absence of phenotypic $(\mathrm{CD} 20+) \mathrm{B}$ lymphocytes. Proliferative responses to the mitogen PHA were severely depressed $($ mean $=810 \pm 39 \mathrm{cpm}$; normal, $>75,000 \mathrm{cpm})$. Ig levels were diminished for age: $\mathrm{IgG}=76 \mathrm{mg} / \mathrm{dl}$ (normal, 172-814), IgM $=10 \mathrm{mg} / \mathrm{dl}$ (normal, 33-108), IgA $=3 \mathrm{mg} / \mathrm{dl}$ (normal, 8-84). Red blood cell ADA activity was absent (normal, 33-100 umol/h per g hemoglobin), diagnostic of ADA deficiency.

The patient did not have a histocompatible sibling donor. Compromised pulmonary status and active parainfluenza infection increased his risks of morbidity and mortality from pretransplant ablative chemotherapy and $T$ lymphocyte-depleted haploidentical bone marrow transplantation. Because of these risks, enzyme replacement therapy with PEG-ADA was instituted. During the period of study PEG-ADA was administered once or twice weekly by intramuscular injections, as described in Results.

Parainfluenza type 2 was treated with aerosolized ribavirin and QOD intravenous immunoglobulin (IVIg), but respiratory function continued to deteriorate during the first 3 wk of therapy. From weeks 3 to 6 of PEG-ADA therapy, the patient required mechanical ventilatory assistance with endotracheal delivery of the ribavirin. After week 6 , his pulmonary status had improved so that mechanical ventilation was not required, although he was still dependent on supplemental oxygen until week 27. Cultures for parainfluenza type 2 remained positive until week 12 of PEG-ADA therapy. Ribavirin was discontinued at week 17 without recurrence of parainfluenza. The patient was discharged from the hospital 22 wk after starting PEG-ADA therapy. After week 25 he received $30 \mathrm{mg} / \mathrm{kg}$ PEG-ADA once weekly and IVIg once monthly. After 1 yr of PEG-ADA therapy, he was shown to have a normal humoral response to $\phi \mathrm{X} 174$, and IVIg was discontinued. He has had no new opportunistic infections, is now growing normally, and no longer requires supplemental oxygen.

Patient 2. Patient 2 is the full-term product of an uncomplicated pregnancy in a 14-yr-old G1P1 woman. She is the product of a consanguineous union between the mother and a maternal uncle. She presented to Children's Hospital San Diego at 3.5 mo of age with failure to thrive and a history of diarrhea. She had an episode of bronchitis, which was treated with ampicillin, 3 wk before admission. The patient's physical examination was remarkable only for evidence of failure to thrive. Less than $1 \%$ of the peripheral blood lymphocytes were $\mathrm{CD} 3+$. Serum Ig levels were diminished: $\mathrm{IgG}=108 \mathrm{mg} / \mathrm{dl}, \mathrm{IgM}<7$ $\mathrm{mg} / \mathrm{dl}, \mathrm{IgA}<7 \mathrm{mg} / \mathrm{dl}$. There was no proliferative response to PHA. Despite one immunization with tetanus toxoid, there was no protective titer to tetanus. Red blood cell ADA activity was absent.

On the 12th hospital day the patient developed fever and tachypnea. Bronchoalveolar lavage fluid grew Pseudomonas but was negative for Pneumocystis carinii or any virus. She responded to tobramycin and ceftazidime. She received intravenous hyperalimentation, IVIg twice weekly, and prophylactic trimethoprim-sulfamethoxazole during hospitalization.

On day 14 of hospitalization, she was started on twice weekly injections of PEG-ADA, as described in Results. 5 wk after beginning PEGADA therapy, rotavirus infection was demonstrated in the patient's stool. Rotavirus cleared by week 6 of PEG-ADA therapy. The patient's immunologic function and nutritional status improved so that she could be discharged from the hospital by week 17 of PEG-ADA therapy. She is presently $11 \mathrm{mo}$ of age with normal growth and development. She continues to receive monthly IVIg but has been hospitalized for only $2 \mathrm{~d}$ in the past $4 \mathrm{mo}$.

\section{Results}

\section{Correction of metabolic abnormalities}

Patient 1. After an initial intramuscular injection of $10 \mathrm{U} / \mathrm{kg}$ body weight, weekly injections of $30 \mathrm{U} / \mathrm{kg}$ PEG-ADA were begun at week 2. From weeks 1 to 5 , preinjection (trough) plasma ADA activity averaged $11.2 \mu \mathrm{mol} / \mathrm{h}$ per ml (Fig. 1). Erythrocyte dAXP fell from $160 \mathrm{nmol} / \mathrm{ml}$ packed cells (a rela- 


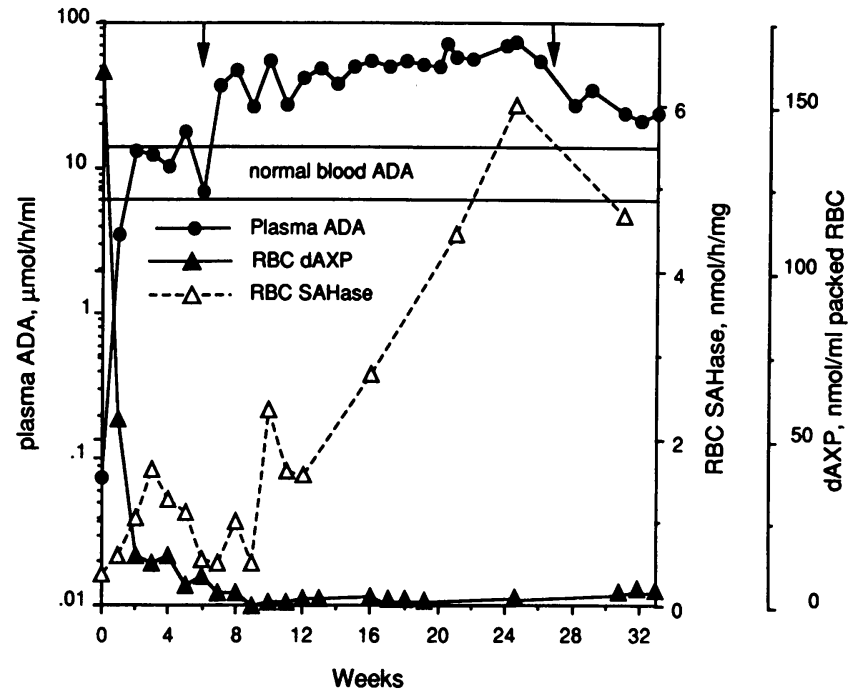

Figure 1. Normalization of plasma ADA activity, RBC dAXP, and RBC SAHase levels in patient 1 during PEG-ADA therapy. During the first 6 wk of therapy, the PEG-ADA dose was $30 \mathrm{U} / \mathrm{kg}$ actual body weight. The arrow at top left indicates when the PEG-ADA dose was increased to $30 \mathrm{U} / \mathrm{kg}$ ideal body weight twice weekly. The arrow at top right indicates when the PEG-ADA dose was decreased to 30 $\mathrm{U} / \mathrm{kg}$ ideal body weight once weekly.

tively low level for ADA-deficient SCID, reflecting blood transfusion) to $9 \mathrm{nmol} / \mathrm{ml}$ packed cells ( normal, $\leq 1-2 \mathrm{nmol} / \mathrm{ml}$ ). Erythrocyte SAHase activity increased from 0.37 to 1-1.6 $\mathrm{nmol} / \mathrm{h}$ per mg protein (mean, 1.26), only $30 \%$ of normal $(4.2 \pm 1.9 \mathrm{nmol} / \mathrm{h}$ per $\mathrm{mg})$.

During week 6, plasma ADA declined to $6.9 \mu \mathrm{mol} / \mathrm{h}$ per $\mathrm{ml}$ and red blood cell (RBC) SAHase fell to $0.56 \mathrm{nmol} / \mathrm{h}$ per $\mathrm{mg}$. The dose of PEG-ADA was increased to twice weekly injections of $30 \mathrm{U} / \mathrm{kg}$ ideal body weight (the 50th percentile of weight for the patient's age). Between weeks 7 and 25, plasma ADA averaged $47.9 \pm 11.7 \mu \mathrm{mol} / \mathrm{h}$ per $\mathrm{ml}$ and $\mathrm{RBC}$ dAXP fell to 1-3 nmol/ml packed cells (Fig. 1); SAHase activity normalized at 4-6 $\mathrm{nmol} / \mathrm{h}$ per $\mathrm{mg}$. At week 27 , a once weekly injection schedule ( $30 \mathrm{U} / \mathrm{kg}$ ideal body weight) was resumed. A therapeutic level of plasma ADA activity, ranging from 21 to $34 \mu \mathrm{mol} / \mathrm{h}$ per $\mathrm{ml}$, and essentially normal levels of RBC dAXP and SAHase activity were maintained after this dose adjustment.

Patient 2. Treatment of the second patient was initiated with twice weekly injections of PEG-ADA ( $30 \mathrm{U} / \mathrm{kg}$ ideal body weight per injection). Plasma ADA activity from weeks 2 to 29 averaged $65.8 \pm 13.9 \mu \mathrm{mol} / \mathrm{h}$ per $\mathrm{ml}$. RBC dAXP declined from a pretreatment level of $695 \mathrm{nmol} / \mathrm{ml}$ packed cells to an average of 7 $\pm 1 \mathrm{nmol} / \mathrm{ml}$ during weeks 7-29 of treatment. RBC SAHase increased from $0.25 \mathrm{nmol} / \mathrm{h}$ per $\mathrm{mg}$ (pretreatment) to an average of $4.1 \pm 1.1 \mathrm{nmol} / \mathrm{h}$ per $\mathrm{mg}$ for the same period.

\section{PEG-ADA-induced $T$ lymphocyte recovery}

Before starting the PEG-ADA therapy, the patients had no evidence of phenotypically normal $\mathrm{T}$ and $\mathrm{B}$ lymphocytes. Circulating $\mathrm{T}$ lymphocytes had a CD7+ CD2+CD3 dim CD4CD8 - phenotype. No CD3 $3^{\text {bright }} \mathrm{CD} 4+$ or $\mathrm{CD} 3^{\text {bright }} \mathrm{CD} 8+\mathrm{T}$ lymphocytes were observed.

During the first weeks of PEG-ADA therapy, no immediate change in the phenotype was observed. Beginning at week 10 in patient 1 and week 5 in patient 2 , the number of CD $3^{\text {dim }}$ lymphocytes increased (Figs. 2, $3 A$, and $4 A$ ). The CD3 ${ }^{\text {dim }}$ lymphocytes were CD4- and CD8-. After the appearance of $\mathrm{CD} 3^{\mathrm{dim}}$ cells, there was a transient increase in the number of $\mathrm{CD} 1+$ cells. $\mathrm{CD} 1+$ cells were detected from weeks 10 to 12 in patient 1 and at week 9 in patient 2 (Figs. $3 A$ and $4 A$ ). The CD1+ cells coexpressed CD3, CD4, and CD8.

$\mathrm{T}$ lymphocytes bearing the mature phenotype of $\mathrm{CD} 3^{\text {bright }}$ CD4+ or $\mathrm{CD}^{\text {bright }} \mathrm{CD} 8+$ appeared only after the increases in $\mathrm{CD}^{\mathrm{dim}}$ and $\mathrm{CD} 1+$ populations (Figs. 2, $3 A$, and $4 A$ ). Dual fluorescence analysis demonstrated that the $\mathrm{CD} 3^{\text {bright }}$ lymphocytes expressed either CD4 or CD8. Dual analysis with antibodies directed against CD4 and CD8 showed that the T lymphocytes did not coexpress both antigens. In patient 1 , the first CD3 ${ }^{\text {bright }}$ cells observed (before week 14) predominantly expressed T cell receptor (TCR) $\gamma / \delta(76 \%)$. By week $15,83 \%$ of the population of CD $3^{\text {bright }}$ cells expressed TCR $\alpha / \beta$ and $17 \%$ expressed TCR $\gamma / \delta$. Subsequently, $>97 \%$ of the CD $3^{\text {bright }}$ cells expressed TCR $\alpha / \beta$. In patient 2, TCR usage was first examined at week 15 , at which time $99 \%$ of the CD $3^{\text {bright }}$ cells expressed TCR $\alpha / \beta$.

\section{Recovery of $T$ lymphocyte mitogen responsiveness}

At the time of initiation of therapy the patients had severely depressed proliferative responses to the mitogen PHA. Despite the increase in the number of $T$ lymphocytes during the first 8-14 wk of PEG-ADA therapy, the PHA response remained absent. In patient 1 , beginning at week $15, T$ lymphocytes had a proliferative response to PHA, but only in the presence of 60 $\mathrm{IU} / \mathrm{ml}$ exogenous IL-2 $(\Delta \mathrm{cpm}=20,160 \pm 3,324$, S.I. $=59$; Fig. $3 B$ ). For patient 2 , a proliferative response dependent on exogenous IL-2 was present at week $9(\Delta \mathrm{cpm}=10,607 \pm 711$, S.I. $=23$ ) $($ Fig. $4 \mathrm{~B})$.

Proliferative responses to PHA that were independent of exogenous IL-2 developed after the IL-2-dependent responses. 3 wk after developing an IL-2-dependent response, patient 1 had proliferative responses to PHA without exogenous IL-2 $(\Delta \mathrm{cpm}=15,640 \pm 1,441$, S.I. $=25)$, although the PHA response was still augmented by exogenous IL-2 ( $\Delta \mathrm{cpm}$ $=25,573 \pm 3,193$, S.I. $=45$ ). A proliferative response to PHA, which was not augmented by exogenous IL-2, was demonstrable 6 wk later. The PHA response without exogenous IL-2 continued to increase and was normal $(\Delta \mathrm{cpm}>75,000)$ by week 28 (Fig. 3 B). 2 wk after the development of an IL-2-dependent response, patient 2 had a normal proliferative response to PHA $(\Delta \mathrm{cpm}=116,571 \pm 11,543$, S.I. $=101)$, which was not dependent on, or augmented by, exogenous IL-2 (Fig. $4 B$ ).

\section{Antigen-specific responses}

The patients were tested for antigen-specific $\mathrm{T}$ lymphocyte proliferation after immunization with tetanus toxoid. In patient 1 , an in vitro proliferative response to tetanus toxoid, which was dependent on exogenous IL-2, was demonstrable by week 19, 2 wk after immunization $(\Delta \mathrm{cpm}=21,164 \pm 5,333$, S.I. $=10)$ (Fig. $3 C$ ). A tetanus toxoid-specific proliferative response, which did not require exogenous IL-2, was detectable by week $21(\Delta \mathrm{cpm}=8,619 \pm 3,762$, S.I. $=21)$. The response without IL-2 was not equal to the IL-2-augmented response until week 24. Subsequent tetanus responses without exogenous IL-2 have persisted (Fig. $3 C$ ). Patient 2 was immunized at week 22 of PEG-ADA therapy. 2 wk later, a normal tetanus toxoid proliferative response not requiring exogenous IL-2 was demonstrable 


\section{WEEK 12}
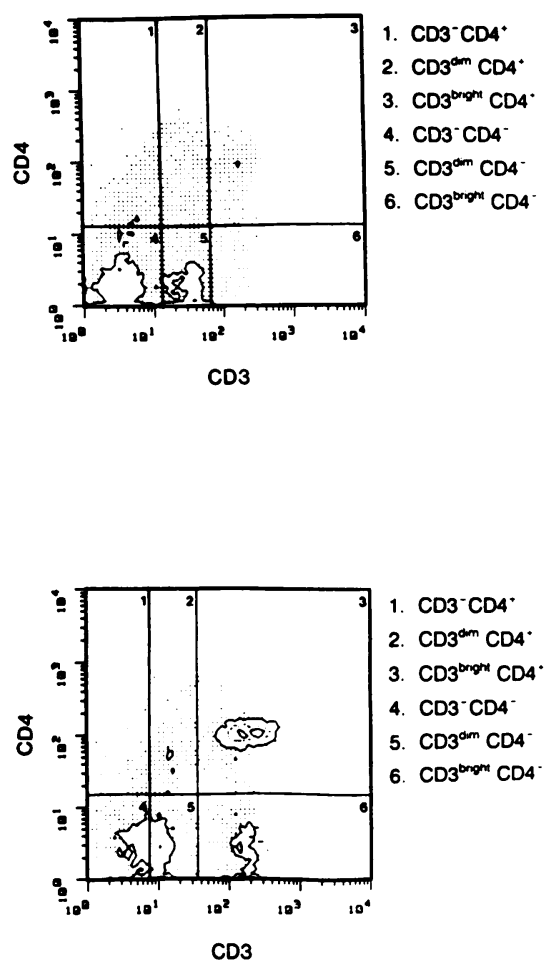

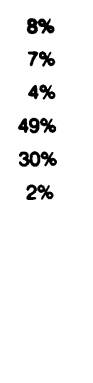

WEEK 25

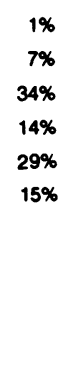

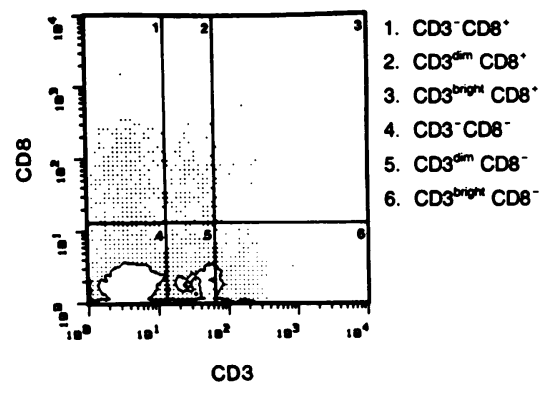

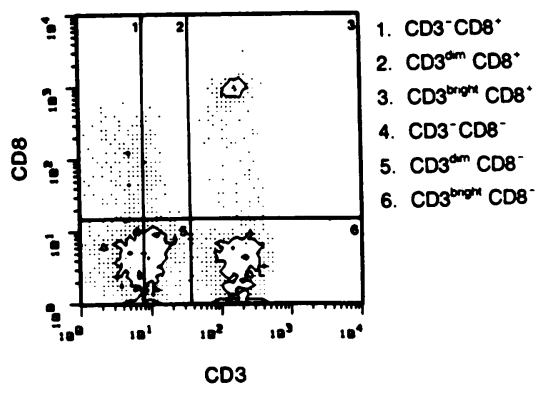

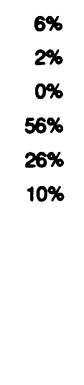

Figure 2. Two-color immunofluorescence histograms demonstrating phenotypic pattern of immune reconstitution in patient 1. Peripheral blood mononuclear cells were stained at weeks 12 and 25 of PEG-ADA therapy with fluoresceinated monoclonal antibody directed against CD3 and phycoerythrin5\% labeled monoclonal anti$5 \%$ bodies directed against 9\% either CD4 or CD8. At

${ }_{17 \%} 12 \mathrm{wk}$, the predominant 27\% populations are 37\% $\mathrm{CD}^{-}{ }^{-} \mathrm{CD} 4{ }^{-} \mathrm{CD}^{-}$cells (zone 4) and $\mathrm{CD}^{\mathrm{dim}}$ CD4-CD8 ${ }^{-}$cells (zone 5). Also present are $\mathrm{CD} 3^{\text {bright }} \mathrm{CD}^{+}{ }^{+}$cells (zone 3). By week 25, the

number of $\mathrm{CD}^{-}$cells has decreased, and $\mathrm{CD} 3^{\text {dim }} \mathrm{CD} 4^{-} \mathrm{CD} 8^{-}$cells (zone 5 ) and $\mathrm{CD} 3^{\text {bright }} \mathrm{CD} 4^{+} \mathrm{CD} 8^{-}$or $\mathrm{CD} 3^{\text {bright }} \mathrm{CD} 4^{-} \mathrm{CD} 8^{+}$cells predominate (zone 3 ). The percentage of positive cells in each zone is also shown. Staining of cells with control fluorescein and phycoerythrin-labeled mouse Ig demonstrated that $99 \%$ of cells were in zone 4 .

$(\Delta \mathrm{cpm}=22,630 \pm 8,799$, S.I. $=30 ;($ Fig. $4 C)$ In both patients 1 and 2 , responses to purified monilia antigen developed in parallel with the tetanus responses (data not shown). The candida responses in both patients were initially dependent on exogenous IL-2, but later became IL-2 independent.

\section{NK assays}

Patient 1 had no initial NK-mediated cytotoxicity. Before starting PEG-ADA therapy, the percentage of specific lysis of $\mathrm{K} 562$ cells was $18 \%$ at $50: 1 \mathrm{EC} / \mathrm{TC}$ ratio (control $=38 \%$, laboratory normal for infants $=42 \pm 14 \%$ ). NK activity became normal by week 23 of therapy with $36 \%$ specific lysis (control $=47 \%$ ). Patient 2 was not tested for NK activity.

\section{Discussion}

Bone marrow transplantation, by introducing metabolically normal lymphoid progenitors, results in normalization of immunological function in children with SCID, including ADA deficiency $(10,11)$. PEG-ADA therapy has been previously reported to induce $T$ lymphocyte responses to mitogens in ADA-deficient SCID (4). $40 \%$ of PEG-ADA-treated patients have developed normal antigen-specific $T$ lymphocyte responses $(12,13)$. This study is the first report of the ontogeny of antigen-specific responses in PEG-ADA-treated patients. In this study we demonstrate that optimal PEG-ADA treatment can result in antigen-specific $T$ lymphocyte responses comparable to those observed after bone marrow transplantation. The pattern of immune reconstitution observed suggests that PEGADA enzyme therapy resulted in maturation of ADA-deficient thymic progenitors into functional $\mathrm{T}$ lymphocytes.
The phenotype of the patients' $T$ lymphocytes after PEGADA therapy is consistent with the maturation of functional T lymphocytes from immature thymic progenitors. After normalization of the plasma ADA activity and metabolic parameters, the number of $\mathrm{CD} 3^{\mathrm{dim}}$ lymphocytes increased. Such $\mathrm{CD} 3^{\mathrm{dim}} \mathrm{T}$ lymphoid progenitors represent an early stage of thymic maturation (14). Although most $\mathrm{CD} 3^{\mathrm{dim}}$ thymic progenitors are also $\mathrm{CD} 4+$ and $\mathrm{CD} 8+, \mathrm{CD} 3^{\mathrm{dim}} \mathrm{CD} 4-\mathrm{CD} 8$ - cells, like those observed in the patients, are also present in normal thymus ( 15 , and Weinberg, K. I., unpublished observations). After the appearance of $\mathrm{CD} 3^{\mathrm{dim}} \mathrm{T}$ lymphocytes, there was a wave of lymphocytes expressing the CD1 antigen, which is a marker of an intermediate, possibly functionally inert, stage of thymic ontogeny (16). CD1+ cells are found in newborn cord blood and bone marrow transplant recipients in whom $\mathrm{T}$ lymphocyte maturation is occurring $(17,18)$. Lymphocytes bearing a mature $\mathrm{T}$ lymphocyte phenotype, i.e., $\mathrm{CD} 3^{\text {bright }} \mathrm{CD} 1-\mathrm{CD} 4+$ CD8 - or CD3 $3^{\text {bright }} \mathrm{CD} 1-\mathrm{CD} 4-\mathrm{CD} 8+$, did not appear until 3 mo after beginning PEG-ADA therapy. As in normal thymic maturation, the first mature $\mathrm{CD} 3^{\text {bright }}$ cells in patient $1 \mathrm{ex}$ pressed TCR $\gamma / \delta(19-21)$. The CD $3^{\text {bright }} \mathrm{TCR} \gamma / \delta$ cells were followed by the appearance of CD $3^{\text {bright }}$ TCR $\alpha / \beta$ cells. TCR usage was analyzed later in patient 2 than in patient 1 , by which time all of the $\mathrm{CD} 3^{\text {bright }}$ cells were $\mathrm{TCR} \alpha / \beta$.

The immunophenotyping results suggest that the normalization of dAdo metabolism by PEG-ADA allowed immature thymic progenitors to differentiate into successively more mature stages of $T$ lymphoid development. The observed pattern is different than what would be expected if PEG-ADA had only allowed the clonal expansion of mature $\mathrm{T}$ lymphocytes, which 

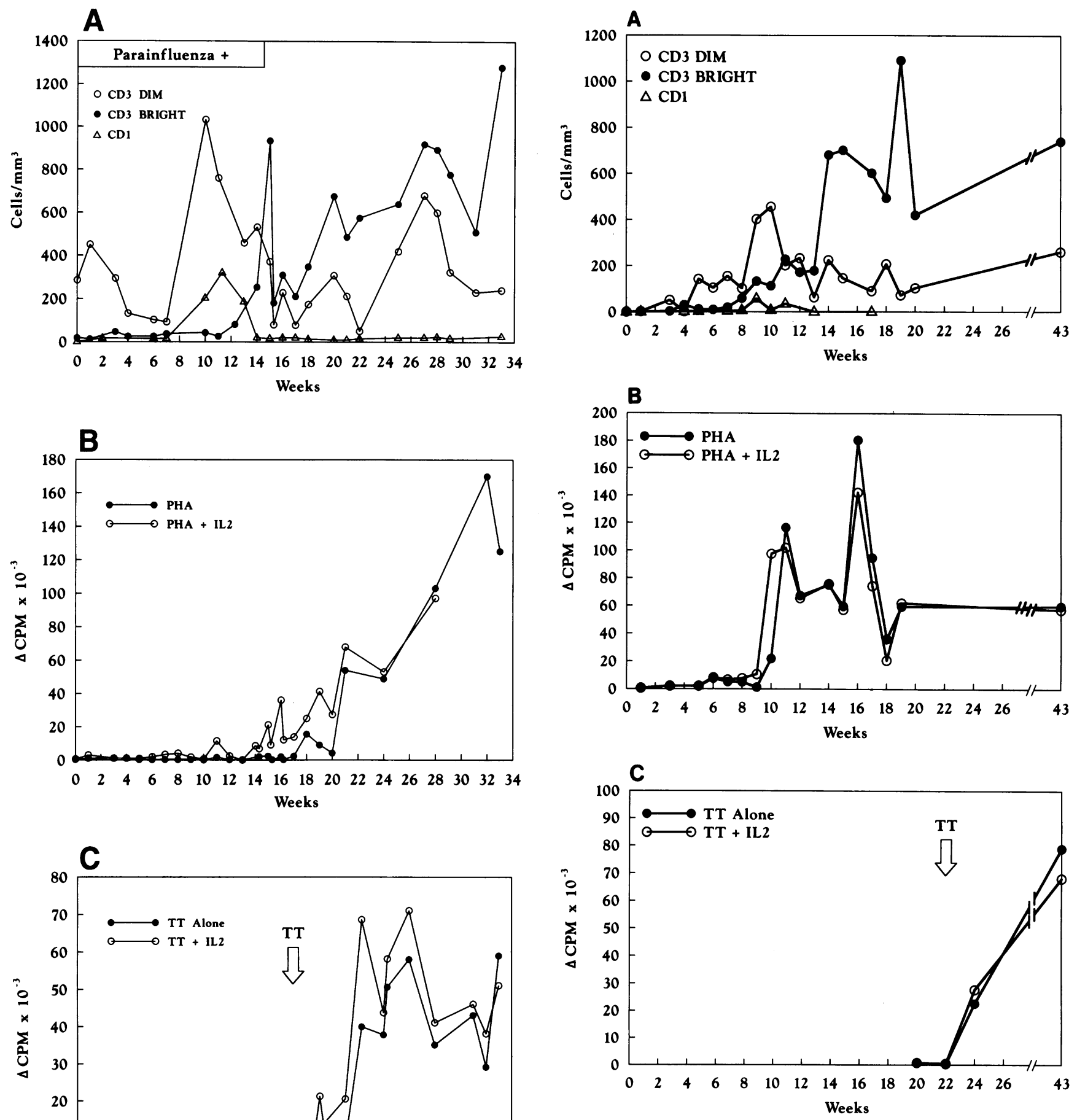

Figure 4. Pattern of immune reconstitution after PEG-ADA therapy in patient 2. PEG-ADA therapy was begun at week $0 .(A)$ The absolute numbers of $\mathrm{CD}^{\mathrm{dim}}, \mathrm{CD}^{\text {bright }}$, and $\mathrm{CDI}^{+}$cells is shown during the first $43 \mathrm{wk}$ of therapy. $(B)$ The proliferative response to PHA is indicated in $\Delta \mathrm{cpm} \times 10^{-3}\left[{ }^{3} \mathrm{H}\right]$ thymidine incorporation. In vitro culture was performed with or without the addition of $240 \mathrm{IU} / \mathrm{ml}$ of recombinant human IL-2. $(C)$ The development of tetanus-specific proliferative responses after immunization with tetanus toxoid (arrow) is indicated in $\Delta \mathrm{cpm} \times 10^{-3}\left[{ }^{3} \mathrm{H}\right]$ thymidine incorporation.

were present before starting PEG-ADA therapy. In the latter case, the immediate appearance of $\mathrm{CD} 3^{\text {bright }}$ cells would have been expected.

The pattern of functional immune reconstitution was also consistent with previous descriptions of $\mathrm{T}$ lymphocyte ontog- 
eny. As lymphocytes bearing a mature $\mathrm{T}$ lymphoid phenotype became detectable in the peripheral blood, a proliferative response to PHA was present only when exogenous IL-2 was added to the cultures. The IL- 2 dependence indicates that T lymphocytes capable of expressing the IL-2 receptor were present but that IL-2 production was absent. After the development of an IL-2-dependent mitogen response, PHA-induced proliferation in the absence of exogenous IL-2 could be detected, demonstrating normal in vitro production of IL-2. The PHA response in the absence of exogenous IL-2 indicates that both IL-2-dependent and IL-2-producing T lymphocytes were present. A similar pattern of initial IL-2 deficiency has been described in the immune reconstitution of bone marrow transplant recipients $(22,23)$.

The development of antigen-specific $T$ lymphocyte responses in the PEG-ADA-treated patients is similar to that seen in patients after bone marrow transplantation or in normal ontogeny (22-24). Mitogen responsiveness normally precedes the development of antigen-specific responses. In patient 1 , PHA-responsive T lymphocytes were followed by antigen-specific responses to tetanus and candida, which were dependent on exogenous IL-2. Patient 2 was immunized with tetanus toxoid later than patient 1 . No early IL-2-dependent phase was observed in tetanus responsiveness. The candida response of patient 2 was initially IL-2 dependent. The need for exogenous IL-2 indicates that relatively normal numbers of antigen-specific IL-2-dependent $T$ lymphocytes are present, but that a deficiency of IL-2-producing antigen-specific $T$ lymphocytes exists. Several weeks later, antigen-specific proliferative responses, which did not require exogenous IL-2, were present. It is not known whether the suboptimal IL-2 production is due to a quantitative decrease in IL-2-producing cells or to a qualitative defect in IL-2 production. The results with exogenous IL-2 suggest that therapy with recombinant IL-2 might be useful in PEG-ADA recipients who have developed IL-2-dependent cells but who still lack adequate IL-2 production.

The eradication of infection coincided with the appearance of mitogen-responsive IL-2-dependent T lymphocytes. After PEG-ADA therapy, patient 1 had normal NK function. It is possible that NK activity was partly responsible for the clearance of the virus. NK cells have been shown to be important in the control of other viral infections (25). The patient's ability to tolerate withdrawal of ribavirin therapy is almost certainly the result of development of antigen-specific responses to parainfluenza.

The studies of these two patients illustrate that PEG-ADA administration must be individualized, based on monitoring of both plasma ADA activity and metabolic abnormalities. Although erythrocyte dAXP declined substantially in the early weeks of patient 1's therapy, trough plasma ADA activity was not maintained above $12 \mu \mathrm{mol} / \mathrm{h}$ per $\mathrm{ml}$, a level used as a guide to therapy in previous patients $(4,12,26,27)$. When red cell SAHase did not normalize, we increased the PEG-ADA injections from once to twice per week and calculated PEG-ADA dose from ideal rather than actual body weight. After the dose modification, plasma ADA activity increased fourfold, and dAXP pools and SAHase activity normalized. The results in this patient indicate that normalization of erythrocyte SAHase activity is an important biochemical guide to the adequacy of enzyme replacement with PEG-ADA.

Two factors may account for the higher dose requirement in patient 1: first, at 6 mo of age he was younger than previously reported patients, who were 2-9 yr old when PEG-ADA was started; and second, he was severely ill and malnourished, a catabolic state in which PEG-ADA, like other proteins, may be eliminated more rapidly. Based on the results with patient 1 , treatment of patient 2 was initiated with twice weekly injections of PEG-ADA, which resulted in a more rapid normalization of metabolic parameters. The pattern of immune reconstitution in patient 2 paralleled that of patient 1 , but it occurred 2-4 wk earlier, suggesting that more rapid metabolic correction may be of immunologic benefit. Because of our experience with these two patients and others in whom higher doses have had no adverse effects (Hershfield, M. S., unpublished observations), we recommend that new patients, particularly if severely ill or $\leq 1 \mathrm{yr}$ of age, should initially be treated with twice weekly doses of PEG-ADA calculated from ideal body weight. The dose can be modified later, based on the biochemical and immunologic response.

This study demonstrates that antigen-specific $\mathrm{T}$ lymphocyte function can be successfully achieved in ADA-deficient SCID after optimal PEG-ADA therapy. Antigen-specific $T$ lymphocyte responses, as described in this report, have developed in $\sim 40 \%$ of patients treated with PEG-ADA $(12,13)$. Further studies of other PEG-ADA-treated patients will be required to determine which factors predict a complete response to PEG-ADA treatment. The quality of immune reconstitution is comparable to that achieved after haploidentical $\mathrm{T}$ lymphocyte-depleted bone marrow transplantation (24). There may be better recovery of humoral immune function in patients who respond to PEG-ADA than in those who show stable engraftment after haploidentical marrow transplantation (28). Unlike bone marrow transplantation, PEG-ADA therapy is not complicated by the risks of cytoreductive chemotherapy, which is frequently required for transplantation in ADA deficiency $(11,29)$. As in T lymphocyte-depleted bone marrow transplants, the antigen-specific $\mathrm{T}$ lymphocytes appear to develop from immature thymic progenitors. Thus, PEG-ADA therapy of SCID is a model for the study of postnatal thymic differentiation.

\section{Acknowledgments}

The authors thank Geralyn Annett, Judith Brooks, and Raymond Chan for their technical assistance with the immunophenotyping and proliferation assays, and Scott Muir for performing the biochemical assays. Felix Burotto performed the flow cytometric analyses. He and Ms. Annett were invaluable in the analysis of the pattern of reconstitution. Dr. William Roberts performed the staining of normal CD3 ${ }^{\mathrm{dim}}$ thymocytes. Dee Wynne and Dr. Eric Groves of the Cetus Corp. supplied the recombinant IL-2.

This work was supported by National Institutes of Health grants AI-25071 (to K. Weinberg) and DK-20902 (to M. S. Hershfield) and a grant from Enzon, Inc. (to M. S. Hershfield).

\section{References}

1. Gelfand, E. W., and H.-M. Dosch. 1983. Diagnosis and classification of severe combined immunodeficiency disease. In Primary Immunodeficiency Diseases. Vol. 19. R. J. Wedgwood, F. S. Rosen, and N. W. Paul, editors. Alan R. Liss, Inc., New York. 65-72.

2. Giblett, E. R., J. E. Anderson, F. Cohen, B. Pollara, and H. J. Meuwissen 1972. Adenosine deaminase deficiency in two patients with severely impared cellular immunity. Lancet. ii:1067-1069.

3. Kredich, N. M., and M. S. Hershfield. 1989. Immunodeficiency diseases caused by adenosine deaminase deficiency and purine nucleotide phophorylase deficiency. In The Metabolic Basis of Inherited Disease. 6th ed. C. R. Scriver, A. L. Beaudet, W. S. Sly, and D. Valle, editors. McGraw-Hill, New York. 1045. 
4. Hershfield, M. S., R. H. Buckley, M. L. Greenberg, A. L. Melton, R. Schiff, C. Hatem, J. Kurtzberg, M. L. Markert, R. H. Kobayashi, A. L. Kobayashi, and A. Abuchowski. 1987. Treatment of adenosine deaminase deficiency with polyethylene glycol-modified adenosine deaminase. N. Engl. J. Med. 316:589-596.

5. Chaffee, S. A., E. R. Stiehm, D. Girault, A. Fischer, and M. S. Hershfield. 1992. IgG antibody response to polyethylene glycol-modified adenosine deaminase (PEG-ADA) in patients with adenosine deaminase deficiency. J. Clin. Invest. 89:1643-1651.

6. Snyder, F. F., J. Mendelsohn, and J. E. Seegmiller. 1976. Adenosine metabolism in phyto-hemagglutinin-stimulated human lymphocytes. J. Clin. Invest. 58:654-666.

7. Hershfield, M. S. 1979. Apparent suicide inactivation of human lymphoblast S-adenosylhomocysteine hydrolase by 2'-deoxyadenosine and adenine arabinoside: a basis for direct toxic effects of analogs of adenosine. J. Biol. Chem. 254:22-25.

8. Hershfield, M. S., and N. M. Kredich. 1980. Resistance of an adenosine kinase-deficient human lymphoblastoid cell line 2to effects of deoxyadenosine on growth, S-adenosyllhomocysteine hydrolase inactivation, and dATP accumulation. Proc. Natl. Acad. Sci. USA. 77:4292-4296.

9. Hershfield, M. S., J. E. Fetter, W. C. Small, A. S. Bagnara, S. R. Williams, B. Ullman, D. W. Martin Jr., D. B. Wasson, and D. A. Carson. 1982. Effects of mutational loss of adenosine kinase and deoxycytidine kinase on deoxyATP accumulation and deoxyadenosine toxicity in cultured CEM human T-lymphoblastoid cells. J. Biol. Chem. 257:6380-6386.

10. Fischer, A., P. Landais, W. Friedrich, G. Morgan, B. Gerritsen, A. Fasth, F. Porta, C. Griscelli, S. F. Goldman, R. Levinsky, and J. Vossen. 1990. European experience of bone-marrow transplantation for severe combined immunodeficiency. Lancet. 336:850-854.

11. O'Reilly, R. J., N. Kapoor, D. Kirkpatrick, N. Flomenberg, M. S. Pollack, B. Dupont, R. A. Good, and Y. Reisner. 1983. Transplantation of hematopoietic stem cells for lethal congenital immunodeficiencies. In Primary Immunodeficiency Disease. Vol. 19. R. J. Wedgwood, F. S. Rosen, and N. W. Paul, editors. Alan R. Liss, Inc., New York. 129-137.

12. Hershfield, M. S., and S. Chaffee. 1991. PEG-enzyme replacement therapy in adenosine deaminase deficiency. In Treatment of Genetic Disease. R. J. Desnick, editor. Churchill-Livingstone, Inc., New York. 169-182.

13. Hershfield, M. S., S. Chaffee, and R. U. Sorensen. Enzyme replacement with PEG-ADA in adenosine deaminase deficiency: overview and case reports of three patients, including two now receiving gene therapy. Pediatr. Res. 33 (Suppl.):S42-S48.

14. Nikolic-Zugic, J., and M. W. Moore. 1989. T cell receptor expression on immature thymocytes with in vivo and in vitro precursor potential. Eur. J. Immunol. 19:1957-1960.

15. Toribio, M. L., C. A. Martinez, M. A. R. Marcos, C. Marquez, E. Cabrero, and A. de la Hera. 1986. A role for T3+4- $6^{-} 8^{-}$transitional thymocytes in the differentiation of mature and functional $\mathrm{T}$ cells from human prothymocytes. Proc. Natl. Acad. Sci. USA. 83:6985-6988.
16. de la Hera, A., M.-L. Toribio, and A. C. Martinez. 1989. Delineation of human thymocytes with or without functional potential by CD1-specific antibodies. Int. Immunol. 1:496-502.

17. Gerli, R., P. Rambotti, C. Cernetti, A. Velardi, F. Spinozzi, A. Tabilio, M. Martelli, F. Grignani, and S. David. 1984. A mature thymocyte-like phenotypic pattern on human cord circulating T-lymphoid cells. Cell. Immunol. 4:461-468.

18. Rappeport, J. M., M. J. Dunn, and R. Parkman. 1983. Immature T lymphocytes in the peripheral blood of bone marrow transplant recipients ${ }^{1}$. Transplantation (Baltimore). 36:674-680.

19. Snodgrass, H. R., Z. Dembic, M. Steinmetz, and H. von Boehmer. 1985. Expression of T-cell antigen receptor genes during fetal development in the thymus. Nature (Lond.). 315:232-233.

20. Haynes, B. F., K. H. Singer, S. M. Denning, and M. E. Martin. 1988. Analysis of expression of $\mathrm{CD} 2, \mathrm{CD} 3$, and $\mathrm{T}$ cell antigen receptor molecules during early human fetal thymic development. J. Immunol. 141:3776-3784.

21. Spits, H. 1991. Human T cell receptor $\gamma \delta+T$ cells. Semin. Immunol. 3:119-129.

22. Welte, K., N. Ciobanu, M. A. S. Moore, S. Gulati, R. J. O'Reilly, and R. Mertelsmann. 1984. Defective interleukin 2 production in patients after bone marrow transplantation and in vitro restoration of defective $T$ lymphocyte proliferation by highly purified interleukin 2 . Blood. 64:380-385.

23. Lenarsky, C., K. Weinberg, J. Peterson, and R. Parkman. 1987. Interleukin 2 (IL-2) restoration of defective in vitro lymphocyte proliferation following bone marrow transplantation (BMT). Blood. 70:310a. (Abstr.)

24. Keever, C. A., T. N. Small, N. Flomenberg, G. Heller, K. Pekle, P. Black, A. Pecora, A. Gillio, N. A. Kernan, and R. J. O'Reilly. 1989. Immune reconstitution following bone marrow transplantation. Comparison of recipients of $\mathrm{T}$ celldepleted marrow with recipients of conventional marrow grafts. Blood. 73:13401350.

25. Biron, C. A., K. Byron, and J. L. Sullivan. 1989. Severe herpesvirus infections in an adolescent without natural killer cells. $N$. Engl. J. Med. 26:1731-1735.

26. Levy, Y., M. S. Hershfield, C. Fernandez-Mejia, S. H. Polmar, D. Scudiery, M. Berger, and R. U. Sorensen. 1988. Adenosine deaminase deficiency with late onset of recurrent infections: results of treatment with polyethylene glycol-modified adenosine deaminase (PEG-ADA). J. Pediatr. 109:114-117.

27. Bory, C., R. Boulieu, G. Souillet, C. Chantin, M. O. Rolland, M. Mathieu, and M. S. Hershfield. 1990. Comparison of red cell transfusion and polyethylene glycol-modified adenosine deaminase therapy in an adenosine deaminase-deficient child. Pediatr. Res. 28:127-130.

28. Ochs, H. D., R. H. Buckley, R. H. Kobayashi, A.-L. Kobayashi, R. U. Sorensen, and M. S. Hershfield. 1992. Antibody responses to bacteriophage $\phi \mathrm{X} 174$ in patients with adeosine deaminase deficiency. Blood. 80:1163-1171.

29. O'Reilly, R. J., C. A. Keever, T. N. Small, and J. Brochstein. 1989. The use of HLA-non-identical T-cell depleted marrow transplants for correction of severe combined immunodeficiency disease. Immunodefic. Rev. 1:273-309. 